\title{
Study of Applied Innovative Talents Training Mode Management based on Combination of Entrepreneurship Education, Professional Education and Humanistic Education
}

\author{
Yuting Chen ${ }^{1, a}$ \\ ${ }^{1}$ Chongqing City Management College, Chongqing, 401331 \\ ${ }^{\mathrm{a}}$ email
}

Keywords: Creative Talents, Humanistic Education, Professional Education, Vocational Entrepreneurship Education

\begin{abstract}
For a long time, cultivate innovative talents has been the focus of development of higher vocational education. But in the actual survey, this paper found that there are many colleges and universities did not recognize the importance of innovation and personnel training. Faced with this situation, the university should give full play to entrepreneurship education, professional education, humanities education an important role in creation of appropriate curriculum, improve the system construction of vocational college courses, to promote cultivation of innovative talents in higher vocational colleges.
\end{abstract}

\section{Introduction}

Social progress and development give new demands university talent training, only with innovative thinking, creative talents to meet the needs of social development, in a favorable position in the competition. Vocational colleges should fully recognize the importance of innovation and personnel training, emphasis on entrepreneurship education, an important role in professional education, humanities education plays in the development of vocational education, improve the innovative personnel training system vocational college, promoting innovation Talents process.

\section{Entrepreneurship Education and Professional Education, the Significance of Humanistic Education}

Equally important position higher vocational colleges entrepreneurship education, professional education and humanities education, the three complement each other, harmonious communion together to promote, not only to enhance the quality of teaching and universities, improve the level of personnel training, and education to reflect the soft Vocational Colleges the corresponding relationship between strength and hard power, new strategies for the university personnel training, therefore, the integration of the three is important [1].

At present, China Vocational Institute entrepreneurship education system is imperfect, in order to promote the smooth development of entrepreneurship education in higher vocational colleges, colleges and universities should attach importance to the importance of professional education and humanities education, and promote mutual integration of entrepreneurship education and professional education and humanities education. For a long time, vocational colleges attached great importance to cultivating students' innovative ability to accelerate innovative teaching mode. Professional Education and Humanities Education in University Students entrepreneurial qualities There are many basic requirements and have some common ground between the students' professional qualities and entrepreneurial qualities, merging three kinds of education can enhance the overall quality of students of colleges, has conducive to the smooth development of entrepreneurship education in higher vocational colleges.

To Achieve Work-study Combination. For a long time, China's higher education deeply influenced by the traditional mode of education, training and vocational colleges is difficult to adapt to social and economic development. Merging Vocational College entrepreneurship education, professional education and humanities education can strengthen communication between 
universities and enterprises, the full use of university, corporate resources to carry out high-quality teaching, students' practical ability to provide a large number of internship opportunities for students, increase social experience, theory and practice. This merging of teaching model can not only solve the practical problems of vocational college students, but also lay a good foundation for entrepreneurial activities, highlighting the central position of students in teaching, engineering combine to achieve educational goals.

Expand Vocational College Students Employment Space. In vocational education, combined with entrepreneurship education, professional education and humanities education for students to be able to create a good atmosphere for learning, deepen students' understanding of entrepreneurship, through entrepreneurship education and professional education, students are able to master certain entrepreneurial basis, the current social situation there is a general understanding of the culture in the invisible student's entrepreneurial qualities, enhance their social competence, so that graduates face fierce social competition will not know what to do, not at a disadvantage in the competition [2]. Enterprise Education can effectively expand students' employment space for a long time, after graduating from vocational college students often choose to embark on the road of corporate recruiters, few students to consider their own businesses, over-reliance on corporate recruiters, often resulting in China's entrepreneurial activities more slowly. Carry out independent entrepreneurial activity can not only ease the employment pressure, but also for the students to achieve the ideal of life to provide an effective way to create large numbers of jobs, reduce government pressure.

\section{The Status of Vocational Entrepreneurship Education, Professional Education and Humanistic Education}

With the development of society, innovative talents have caused concern in the community, business demand for more and more innovative talents. But look at the status quo of Talents in Higher Vocational Colleges can find many vocational colleges have not recognized the importance of innovation and personnel training, entrepreneurship education have failed to recognize the importance of professional education and humanities education in Training in innovative personnel training needs caused widespread concern in the community. Roughly opinion, the presence of major entrepreneurship education colleges, professional education, humanities education fusion following question:

Currently, many vocational colleges have not recognized the importance of entrepreneurship education development, teaching students to focus on vocational skill training. Social competition, not only requires students to have a strong professional skills to meet the needs of social production, also requires students to have a good sense of entrepreneurship and high personal qualities, only to meet the above requirements talent, talent is the most popular social . But it can be seen from the current personnel training in higher vocational colleges, colleges and universities will be professional skills as a key direction, ignoring the importance of entrepreneurship education and humanities education. Not even many vocational colleges offer career guidance programs, and no professional teachers to guide students, students' understanding of employment very little understanding of the business out of the question, employment preparation and training work sense of entrepreneurship are stranded. In addition, compared with the universities, the proportion of courses Higher Vocational Humanities Education also far below the university, mainly because for a long time. Teaching Orientation Vocational College is to develop students' professional skills, to cultivate professional and technical personnel, under the influence of this education target, Humanistic Education in Higher Vocational Colleges have long been neglected, ideological and political education work can not be carried out, overall quality of students and individual moral cultivation lift out of the question.

Teaching in vocational colleges not fully aware of entrepreneurship education, the importance of professional education and humane education, integration is an important factor innovative personnel training is in higher vocational colleges, the same lack of sound education system is the integration of management influence in High Vocational Colleges important reasons for personnel training. Conscious decision to act, even though some institutions is intended to promote the 
integration of entrepreneurship in vocational education, professional education, humanities education, but due to lack of appropriate management systems, integration of vocational education institutions is difficult to effectively carry out the work. Entrepreneurship education, professional education, humanities education students to develop the role of different management methods also differ, therefore, colleges and universities to establish a corresponding management system, developed different assessment criteria for different education classified management, and to develop appropriate incentives, to reward outstanding person, the punishment for laggards to make vocational education Colleges administrators have full attention. Improve the education management system not only ensures the smooth development of the work of higher education, but also to stimulate the enthusiasm of teachers and enthusiasm to enhance the level of culture innovative talents colleges, vocational colleges to improve the quality of teaching, for the society a large number of outstanding talent [4].

\section{Importance of Vocational Entrepreneurship Education, Professional Education and Humanistic Education}

Innovative talents not only an important requirement of social development, but also improve the competitiveness of an important factor in higher vocational colleges, vocational colleges should pay attention to the importance of innovation and personnel training, colleges and universities combined with the actual school, a large number of talents for the society.

It is Conducive to Innovation and Personnel Training. Innovative nation-building is one of the major strategic vision put forward by the party and state leaders, is a major strategic concept of scientific development is to adapt to social development and achieve sustainable development of China's major decisions. China is building an innovative country through long-term development summed up an important experience. Compared with developed countries, the modernization of our late start, but also to buy some advanced technology from developed countries, the long-term development has proved that China's modernization in order to achieve development goals, we must accelerate the pace of innovation Talents and the Creative Talents raised to a height of national development, in addition, law than without him. The rapid development of science and technology, high-tech fields in various countries to innovate, but that does not mean that innovation-oriented country has been built. Innovative country will not only sense of innovation and integration into the national culture. The key innovation of nation-building is to enhance the nation's capacity for independent innovation, cultivate innovative talents is the core of the development of an innovative country. Education has an important role in nurturing creative talents, vocational colleges as an important part of education in China, capable of handling large number of talents for the country, vocational colleges undertakes the important function of personnel training, scientific research and services, is the national innovation implementation of the main system [6]. Entrepreneurship education, professional education, humanities education as the three major aspects of the educational system in vocational colleges play a different role in personnel training in higher vocational colleges to promote mutual integration of the three, to improve the education system, vocational colleges, high lift Vocational schools teaching quality and level of training personnel.

The Important Method to Solve the Employment Issue of College Graduates. Rapid economic development, so that social competition even more intense. The number of college graduates increased year by year, the number of jobs is very limited, the interaction of these factors makes the employment of college students is very prominent, the lower employment rate of university. In this case, with some work experience, outstanding professional skills, ability to work, innovative students to occupy a favorable position in the fierce competition to find suitable jobs. In contrast, the ability to work is weak, the lack of innovation in the competition the students in a passive position. Today, the employment of college students not only about the student's own development, but also the whole nation has become concerned about the hot, direct impact on China's economic development and social progress, relating to social stability and harmony. Creative Talents in Higher Vocational Schools not only can effectively alleviate social pressures, and to some extent, can solve the difficult problem of employment of college. 


\section{The Integration of Vocational Education Training Program Creative Talents}

Entrepreneurship education, professional education and humane education, integration has become the development trend of higher vocational education institutions and social development is today an important requirement for higher education. Vocational colleges should follow the trend of social development, promote entrepreneurship education in the teaching process, professional education and humane education, integration, to play professional characteristics of different universities and disciplines, promote the overall development of students, the only way to Higher Vocational Colleges high quality innovative talents.

Changing Ideas. Thoughts from the professional skills of personnel training in vocational college transition to an integrated personnel training, educators vocational colleges should change the concept, fully aware of the importance of innovation and personnel training. Development and social progress of science and technology not only requires students to have a high level of expertise, as well as having a noble morality. Vocational educators should fully recognize the importance of entrepreneurship education, professional education, humanities education, recognizing the role of students in different educational culture play. Enterprise Education can help students to do pre-employment preparation, so that students in the face of intense social competition will not know what to do, at the same time, students entrepreneurial awareness, overly dependent on business recruitment, so that students recognize the value of life in entrepreneurship achieve an important role in the promotion of innovative ability. It is able to carry out professional education to improve students 'professional skills, vocational colleges to improve teaching methods, to improve students' skills for the society a large number of professional and skilled personnel to meet the needs of social production. Humanities education can help improve students' ideological and moral standards, help develop a sound personality, and promote the process of building a harmonious society.

Establish and Improve of Education Management System. Sound education management system is important for the development of university education. Integration of entrepreneurship education, professional education, humanities education can effectively promote the progress and development of vocational education and improve the level of Creative Talents Training College. Due to the different focus of entrepreneurship education, humanities education and professional education, colleges and universities to develop appropriate management methods and assessment criteria for entrepreneurship education, professional education and humanities education management and assessment. Vocational colleges should establish appropriate curriculum for entrepreneurship education, the development of higher vocational colleges in different semesters different educational content, progressive, entrepreneurial guidance to students, help students to do pre-employment preparation, and distribution corresponding teaching tasks, regular student assessment grades who failed to arrange rebuilt. For professional education, vocational colleges should pay attention to the combination of theory and practice, increase the proportion of the entire practice course curriculum system, and after completion of theoretical education, students are required to carry out teaching practice, students hands-on ability. For humanities education in terms of higher vocational colleges to choose the appropriate materials to carry out teaching, regular examinations, included in the corresponding credits.

3 , the establishment of a comprehensive system of cooperation

Entrepreneurship education, integration of professional education and humanities education requires a comprehensive system of cooperation as a safeguard. Professional education you need to have a special practice field operation sites, humanistic education teachers need to be a professional culture. Therefore, higher vocational colleges should be established a comprehensive system of cooperation, strengthen school-enterprise cooperation. Businesses that offer higher vocational colleges practice site, and enterprises with professional technical equipment, through visits to enterprises, students can close contact with professional equipment, and during the visit, the students are able to understand the history of the development of enterprises, to understand the business different Operations department for future entrepreneurs lay a good foundation; contacts with business executives to help students learn entrepreneurial success, entrepreneurs learn 
indomitable will and courage to face setbacks, students good entrepreneurial mindset. Governance through school-enterprise cooperation, vocational colleges to establish a professional practice base, to develop students practical skills, but also to grasp the latest development, providing the latest jobs for students. In addition, higher vocational colleges should regularly scheduled teacher training, to enhance the professional skills of teachers and improve the quality of university personnel training; invite relevant experts offer educational seminars for students to indicate the direction of development, to solve students' growth encountered problems and promote the comprehensive growth of students, in favor of innovative talents in higher vocational colleges [8].

Faced with a highly competitive social environment, higher vocational colleges should pay attention to innovation and personnel training, and vocational colleges as the development goals, and promote vocational college students employment, a large number of talents for the society. In the process of teaching, vocational colleges to recognize that entrepreneurship education, professional education and humanities education in the importance of talent development, and promote mutual integration of the three, and jointly promote the cultivation of innovative talents in higher vocational colleges.

\section{References}

[1] Wu Yingjian. Exploring Innovative Talents Training in Vocational College [D]. Fudan University, 2013.

[2] Wang Yimin. Innovative Talents Training Model of Higher Vocational College [J]. Vocational Technical Institute, 2011, 08: 4-8.

[3] Zhang Yaoxiang, Jiang Lijun. Vocational entrepreneurship education and professional education Fusion choice [J]. Chinese higher education, 2011,20: 46-47.

[4] Zou Lulu. Practical training model based on innovation and entrepreneurship education [J]. professional education and the integration of science Wenhui (in Xunkan), 2015,05: 29-30.

[5] Zheng Wei. Analysis of Innovative Talents Training in Vocational College [J]. Jilin Province Economic Management Cadre College, 2015,05: 74-75.

[6] Xiao Jiaodi. practice vocational entrepreneurship education and professional education training model to explore the integration [J]. Chinese Vocational and Technical Education, 2014,09: 87-91.

[7] Li Jin. Problems and Solutions Ulrich vocational entrepreneurship education and professional education Fusion [J]. Higher Vocational Education (Journal of Tianjin Professional University), 2014, 02: 3-6

[8] He Bin. Innovative education + entrepreneurship education, Cultivating New Talent tour Reservoir - Higher Colleges of Tourism Major innovative training model [J]. Science Advisory (SCIENCE • management), 2013,07: 168- 169. 